\title{
Paroxysmal Atrial Fibrillation
}

National Cancer Institute

\section{Source}

National Cancer Institute. Paroxysmal Atrial Fibrillation. NCI Thesaurus. Code C80391.

A disorder characterized by an electrocardiog raphic finding of episodic atrial fibrillation with abrupt onset and termination. 